\title{
HYPOTHALAMIC NEURONS RESPONDING TO HEMODYNAMIC INPUT AND TO STIMULATION IN THE PONS MAY INFLUENCE ADRENOCORTICOTROPIN RELEASE ${ }^{1}$
}

\author{
DREW E. CARLSON, ANNE DORNHORST, ${ }^{2}$ JANICE W. MARAN, ${ }^{3}$ AND DONALD S. GANN ${ }^{4}$ \\ Sections of Physiology-Biophysics and Surgery, Division of Biology and Medicine, Brown University, Rhode Island Hospital, \\ Providence, Rhode Island 02902
}

Received March 21, 1983; Revised August 22, 1983; Accepted October 4, 1983

\begin{abstract}
Experiments were designed to identify hemodynamically sensitive neurons in the mediodorsal hypothalamus and to determine if they were also sensitive to electrical stimulation of areas in the dorsal rostral pons that were implicated previously in the control of adrenocorticotropin (ACTH) release. Cats were anesthetized with chloralose and urethane, immobilized with gallamine, and artificially respired. Hemodynamic stimuli included constriction (CC) of the supradiaphragmatic inferior vena cava to reduce venous return and sinusoidal volume pulsation (RA) of the right atrium $(1 \mathrm{ml}$ peak at $1 \mathrm{~Hz}$ ). Previously, CC was shown to facilitate and RA was shown to inhibit ACTH release. Electrical stimulation in the pons consisted of single shocks $(500 \mu \mathrm{A} \mathrm{DC}, 0.05 \mathrm{msec}$, negative-to-tip) delivered on each of an array of three or four bipolar co-axial electrodes in the pons. Twenty-three neurons were tested with only RA. Of these, two were inhibited, two were facilitated, and 19 did not respond. Thirty-two neurons were tested with CC. Of these, nine were inhibited, nine were facilitated, and 14 did not respond. Seventeen neurons that responded either to RA or to $\mathrm{CC}$ were tested with stimulation in the pons. Of these, three were orthodromically activated and two were inhibited from a total of eight pontine sites. Six of the eight sites were within $300 \mu \mathrm{m}$ of an area shown previously to contain neurons that responded to CC. Of 31 additional sites that were stimulated, but at which stimulation did not drive neurons that responded to hemodynamic stimuli, 26 were located more than $300 \mu \mathrm{m}$ from this area $\left(p<0.01, \chi^{2}\right.$ test $)$. The data suggest that some hypothalamic neurons involved in the hemodynamic control of ACTH release receive a projection from or through the dorsal raphe nucleus medially, and the ventral locus ceruleus, locus subceruleus, and underlying reticular formation laterally. However, other neurons may receive projections that bypass these regions.
\end{abstract}

Several hypothalamic areas that receive afferent input from cardiovascular receptors (Grizzle et al., 1975; Kannan et al., 1981; Thomas and Calaresu, 1972) are thought to modulate a variety of autonomic and neuroendocrine functions. Grizzle and colleagues (1975) identified neurons within the mediodorsal hypothalamus that responded to stretch of the right atrium. Because both the mediodorsal hypothalamus (Grizzle et al., 1974) and the

\footnotetext{
${ }^{1}$ We thank Kathleen T. Cruz for preparing the manuscript. This work was supported in part by National Institutes of Health Grant AM26831.

${ }^{2}$ Present address: Veterans Administration Medical Center, 10701 East Boulevard, Cleveland, $\mathrm{OH} 44106$.

${ }^{3}$ Present address: Department of Biological Research, McNeil Pharmaceutical, Spring House, PA 19477.

${ }^{4}$ To whom correspondence should be addressed, at Rhode Island Hospital, 593 Eddy Street, Providence, RI 02902.
}

right atrial receptors (Cryer and Gann, 1974; Baertschi et al., 1976) were implicated in the control of the release of adrenocorticotropin (ACTH), it was suggested that these neurons participated in this process. However, the route by which cardiovascular signals passed through the brainstem to the hypothalamus remained undefined. Furthermore, the effect of stretch of the right atrium as it was performed in this previous study upon ACTH release was not determined. Thus, the neuronal responses that were observed could not be correlated with specific hormonal changes. In the present study, we have employed cardiovascular stimuli whose effect on the release of ACTH has been described (Gann et al., 1978) to test hypothalamic neurons. We have also tested the neurons for orthodromic responses to electrical stimulation of areas in the dorsal rostral pons which were implicated previously (Ward et al., 1976) in the control of ACTH release. Our results suggest that there are 
pathways from or through groups of cardiovascular neurons in the dorsal rostral pons (Gann et al., 1977, 1978; Ward et al., 1980) that project to a number of areas in the mediodorsal hypothalamus. Our data are consistent with the participation of these projections in the hemodynamic control of ACTH release. Our data suggest also that some hypothalamic neurons participate in other autonomic or neuroendocrine functions and/or receive inputs that bypass the dorsal rostral pons. It appears, then, that the mediodorsal hypothalamus integrates cardiovascular information passing over several pathways within the brainstem in order to produce a coordinated neuroendocrine and autonomic response under a variety of circumstances. Preliminary reports of these results have appeared (Carlson et al., 1981; Gann et al., 1977, 1978).

\section{Materials and Methods}

Thirty-five cats were anesthetized with choralose $(40$ $\mathrm{mg} / \mathrm{kg})$ and urethane $(200 \mathrm{mg} / \mathrm{kg})$ following induction with chloroform. After tracheal intubation, catheters were placed in the femoral vein and artery for measurement of central venous and arterial pressures, and in the jugular vein for delivering volume pulsation to the right atrium as has been described previously (Baertschi et al., 1976). In some experiments, the carotid arteries were isolated in the neck so that they could be occluded to reduce the activity of the carotid arterial baroreceptors. Cats were immobilized with gallamine triethiodide and respired artificially. Supplemental anesthesia was administered as required to maintain pupillary constriction.

In 17 experiments, a thoracotomy was performed in order to place an inflatable cuff around the supradiaphragmatic inferior vena cava. Then the femoral venous catheter was adjusted to ensure that it passed through the cuff to record the pressure rostral to the cuff near the right atrium. The chest was closed, and residual air was evacuated.

In all cats a craniotomy was performed. Microelectrodes for extracellular recordings were placed stereotaxically into the medial hypothalamus using the dorsal approach. An array of three or four bipolar co-axial stimulating electrodes was advanced at an angle of $45^{\circ}$ caudal from vertical through the cerebellum and into the dorsal rostral pons ipsilateral to the sites of recording.

Several cardiovascular manipulations were employed to change the activity of cardiovascular receptors in the periphery. Right atrial volume pulsation, during which 1 $\mathrm{ml}$ of blood was pumped in and out of the right atrium at a rate of $1 \mathrm{~Hz}$, has been shown to increase the activity of right atrial $B$ fibers and of septal $A B$ fibers and to decrease the activity of left atrial $B$ fibers and of arterial baroreceptors (Baertschi et al., 1976). Constriction of the supradiaphragmatic inferior vena cava has been shown to mimic the cardiovascular changes that accompany hypotensive hemorrhage (Bolton, 1910; Gann et al., 1978; Ward et al., 1980). Caval constriction reduced venous return and led to decreased arterial pressure. Thus, the activity of cardiovascular receptors within the venous, pulmonary, and arterial segments was reduced. In some trials, the fall in arterial pressure was minimized by shunting blood from the abdominal vena cava proximal to the cuff into the aorta with a computer-controlled pump, as has been described previously (Gann et al., 1978; Ward et al., 1980). Because the venous-arterial shunt did not exceed $10 \%$ of the cardiac output, and because the venous blood was shunted to a site distal to the aortic arch, it was unlikely that this procedure increased the stimulation of the arterial chemoreceptors.

Extracellular recordings were made with etched stainless steel microelectrodes ( $2-\mu \mathrm{m}$ tips, 1 megohm, 15 cats), glass-coated platinum electrodes $(2-\mu \mathrm{m}$ tips, 1 megohm, six cats), or glass micropipettes filled with $0.5 \mathrm{M} \mathrm{KCl}$ and $10 \%$ horseradish peroxidase (Sigma type 6 ) in $0.1 \mathrm{M}$ Tris buffer, $\mathrm{pH} 8.5$ (2 to 10 megohms, 14 cats). Standard amplification techniques were used. The signals were monitored with a loudspeaker, displayed with a storage oscilloscope, and passed through a voltage level discriminator. Output from the discriminator was displayed on a polygraph and was led to a Nova 800 computer for recording the time of each impulse on a magnetic disk. An on-line record of mean firing rate and mean venous and arterial pressures was displayed on a Tektronix 40101 graphics terminal. During testing, the amplified electrical signal from the electrode tip was monitored carefully.

During cardiovascular testing, the average firing rate of a recorded cell was computed during consecutive periods of $30 \mathrm{sec}$ each. At least three trials of right atrial pulsation lasting $3 \mathrm{~min}, 3 \mathrm{~min}$, and $4.5 \mathrm{~min}$ were used to test neurons. The trials were separated by rest periods of 3 and $4.5 \mathrm{~min}$. The order of these trials and rest periods was chosen randomly to minimize the chance of synchrony of the stimulus with spontaneous fluctuations in neuronal activity. Cells were classified as responsive to atrial pulsation if they had a significant change in their average firing during or following the cessation of the trials. Analysis of variance corrected for repeated measures in the same cell over time (Winer, 1971) was used to examine the mean firing in consecutive 30 -sec periods for $1.5 \mathrm{~min}$ prior to atrial pulsation, for the first 3 min of pulsation, and for the 2 min following pulsation. To determine if neurons responded to caval constriction, we examined the cross-correlation of mean arterial pressure with average neuronal activity during one or more trials of constriction. In previous work (Ward et al., 1980 ), neurons that changed their firing rates significantly during caval constriction had significant crosscorrelations between the neuronal activity and the mean arterial pressure during a complete stimulus trial. In all cases, $p<0.05$ was required to classify a neuron as responsive.

Neurons were tested also with single shocks $(0.05 \mathrm{msec}$, $500 \mu \mathrm{A} \mathrm{DC}$ negative-to-tip, $0.5 \mathrm{~Hz}$ ) to each of the stimulating electrodes placed in the pons. None of the neurons described in the present report was activated antidromically as judged by the commonly accepted criteria of constant latency of response, high-frequency following, and collision with a spontaneous impulse. A number of cells were driven orthodromically as judged by the change in mean firing in response to 60 to 120 repeated stimulations. A neuron was classified as facilitated if pontine stimulation increased its rate of firing more than $20 \%$. A neuron was classified as inhibited if stimulation decreased its rate of firing more than $20 \%$. 
In cats in which neurons were recorded with metal electrodes, lesions using $100 \mu \mathrm{A} \mathrm{DC}$ for 10 to $15 \mathrm{sec}$ were made at the sites of recording and stimulation. Recording electrodes were not reused. Each cat was then perfused with normal saline followed by $10 \%$ formalin, and the brain was removed and stored in formalin for at least 1 week. In cats in which neurons were recorded with micropipettes, horseradish peroxidase was iontophoresed (5-msec pulses of 5 to $8 \mu \mathrm{A}$ cathodal current at $100 \mathrm{~Hz}$ for $5 \mathrm{~min}$ ) to mark the sites of recording. Sites of stimulation were lesioned as discussed above. Each cat was then perfused with cold $\left(4^{\circ} \mathrm{C}\right) 0.1 \mathrm{M}$ phosphate-buffered saline followed with $2.5 \%$ glutaraldehyde. The brain was removed and placed in $2.5 \%$ glutaraldehyde for 3 days and then in 15\% sucrose for 6 days to 3 weeks. Sagittal sections $(35 \mu \mathrm{m})$ were cut from frozen tissue on a sliding microtome. Formalin-fixed material was stained for cells or for fibers. Glutaraldehyde-fixed material was incubated with pyrocatechol and $p$-phenylenediamine (Hanker et al., 1977) for visualization of peroxidase. The locations of the sites of recording and stimulation were identified with the aid of the atlases of Snider and Niemer (1961), Bleier (1961), and Berman (1968). Hypothalamic sites were projected onto the coronal planes of Snider and Niemer (1961). Pontine sites were projected onto the coronal planes of Berman (1968). In four cats, the sites of recording could not be located histolog. ically. Data from these experiments were not included in the present report.

\section{Results}

One hundred and one neurons were subjected to cardiovascular testing. However, a majority of these were rejected because the amplitude of the spike changed during the testing or because the neuron was lost. Only neurons that gave stable recordings of consistent quality were included in the present report.

Response to right atrial pulsation. Twenty-three neurons were tested with only volume pulsation of the right atrium. Of these, only four showed significant responses. Figure 1 shows the response of a neuron located in the dorsomedial nucleus (see Fig. 6) that increased its firing during four trials of atrial pulsation. The response during the first trial was most marked. The mean response to these four trials that is shown in the lower right-hand corner of Figure 1 was significant $(p<0.05)$. Although there appeared to be a decrease in firing at the offset of each trial, it was possible that the response was sustained only during the first $3 \mathrm{~min}$ of pulsation. However, a trial of 1.5 min of pulsation (not shown) was followed also by reduced firing. The only other neuron that was activated during pulsation also decreased its firing following two of the three trials to which it was tested.

Figure 2 (top record) shows the response of another neuron during three trials of pulsation prior to the constriction of the carotid arteries. There was no significant response. Figure 2 (bottom record) shows the response of the same neuron to atrial pulsation during constriction of the carotid arteries. Carotid occlusion led to a significant increase in the spontaneous rate $(p<0.02)$. During pulsation there was a decrease in firing after $1 \mathrm{~min}$. The mean response to these three trials was significant $(p<$
0.05). This neuron also increased its firing during a small hemorrhage of $5 \mathrm{ml} / \mathrm{kg}$ withdrawn over $1 \mathrm{~min}$, held out for $2 \mathrm{~min}$, and reinfused over $1 \mathrm{~min}$. One other neuron was inhibited during right atrial pulsation. However, it responded in the absence of carotid occlusion.

Response to caval constriction. Thirty-two neurons were tested with constriction of the supradiaphragmatic inferior vena cava by an inflatable cuff. Of these, nine decreased their firing during the stimulus. The spontaneous rates of these cells ranged from 0.67 to $5.5 \mathrm{~Hz}$ (mean $3.0 \pm 0.6$ ). Figure 3 shows the response of one of these neurons. The firing decreased during each of three trials of caval constriction. Cross-correlation of the neu-

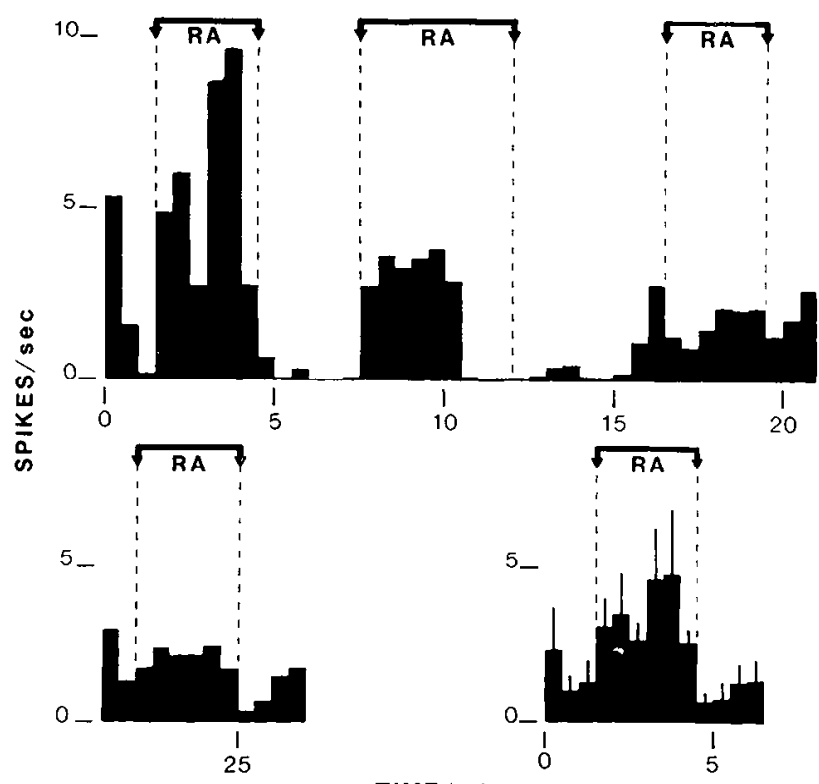

TIME (min)

Figure 1. Firing rate of a single neuron during four trials of right atrial pulsation ( $R A$ ) (top and lower left-hand records) and mean firing rate before, during the first $3 \mathrm{~min}$ of, and after these trials (lower right-hand record) are shown. Error bars indicate $\pm 1 \mathrm{SEM}$.

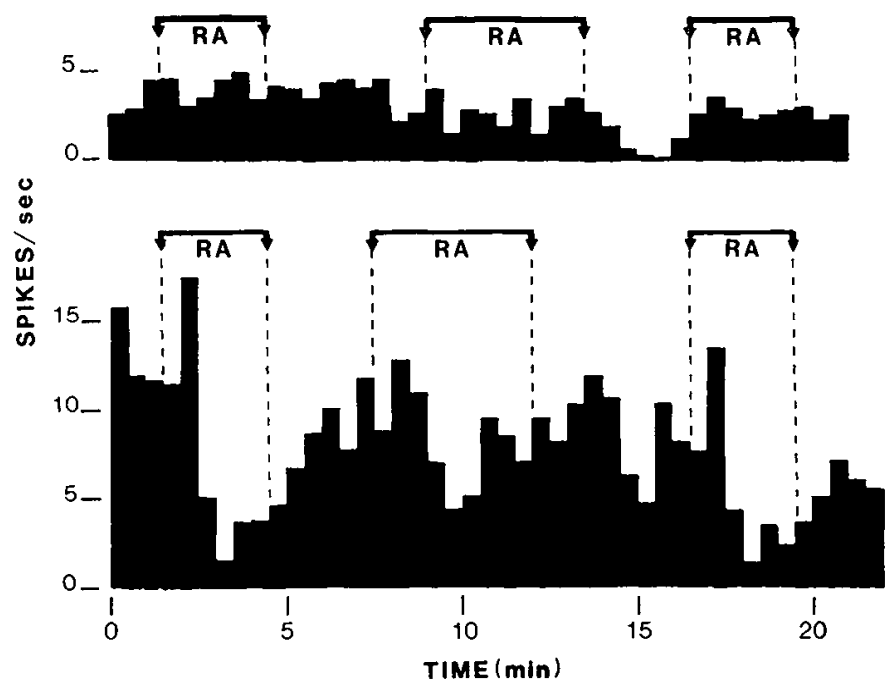

Figure 2. Firing rate of a single neuron during six trials of $\mathrm{RA}$ in the absence (top record) or in the presence (bottom record) of carotid constriction. 


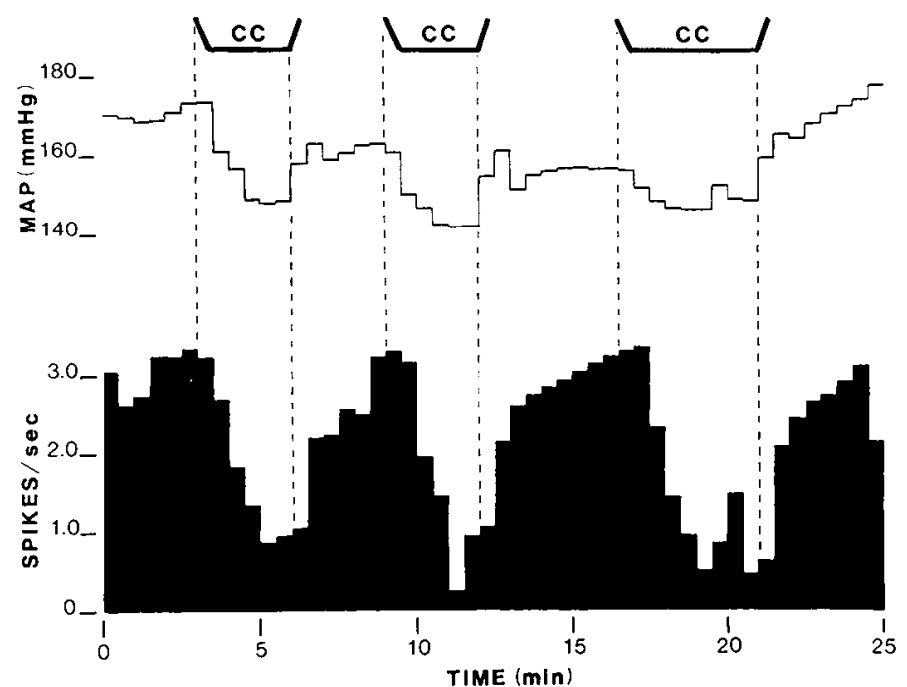

Figure 3. Firing rate of a single neuron during three trials of constriction of the supradiaphragmatic inferior vena cava $(C C)$.

ron's activity with arterial pressure yielded a maximum at a lag of one 30 -sec period $(r=0.74, p<0.01)$. The inhibition of some of the neurons that occurred during caval constriction was less marked. In particular, the four neurons inhibited by caval constriction that were most posterior showed the smallest mean changes in firing (mean $-20 \%$, range -12 to $-32 \%$ ), whereas the five that were more anterior showed larger changes (mean $-49 \%$, range -38 to $-61 \%$ ).

Nine neurons increased their firing during caval constriction. The spontaneous rates of these cells ranged from 0.46 to $9.8 \mathrm{H} /$ (mean $3.8 \pm 1.2$ ). Figure 4 (top record) shows the response of one of these neurons. The firing increased during each of four trials of caval constriction. Cross-correlation of the neuron's activity with arterial pressure yielded a minimum at zero lag ( $r=$ $-0.62, p<0.01$ ). In general, the responses of all of the cuff-activated neurons were marked with minimal correlation coefficients between the firing rate and the arterial blood pressure ranging from -0.48 to -0.80 , and all but one was significant at the $1 \%$ level or better. Fourteen neurons did not respond to caval constriction.

The neuron shown in Figure 4 also responded to volume pulsation of the right atrium. Figure 4 (bottom record) shows its response. The firing increased transiently at the onset of each trial of pulsation $(p<0.01)$. In all, six neurons that were found to be responsive to caval constriction (four inhibited, two facilitated) were tested with volume pulsation of the right atrium. Of these, the neuron shown in Figure 4 was the only one to show a significant response to pulsation alone. However, another neuron that was facilitated by caval constriction was tested with two trials of pulsation while the caval cuff was inflated. Under this condition, the pulsation led to a decrease in firing. This result has appeared in a preliminary report of these experiments (Gann et al., 1978).

The strongest correlations for all of the 18 neurons that responded during caval constriction were obtained

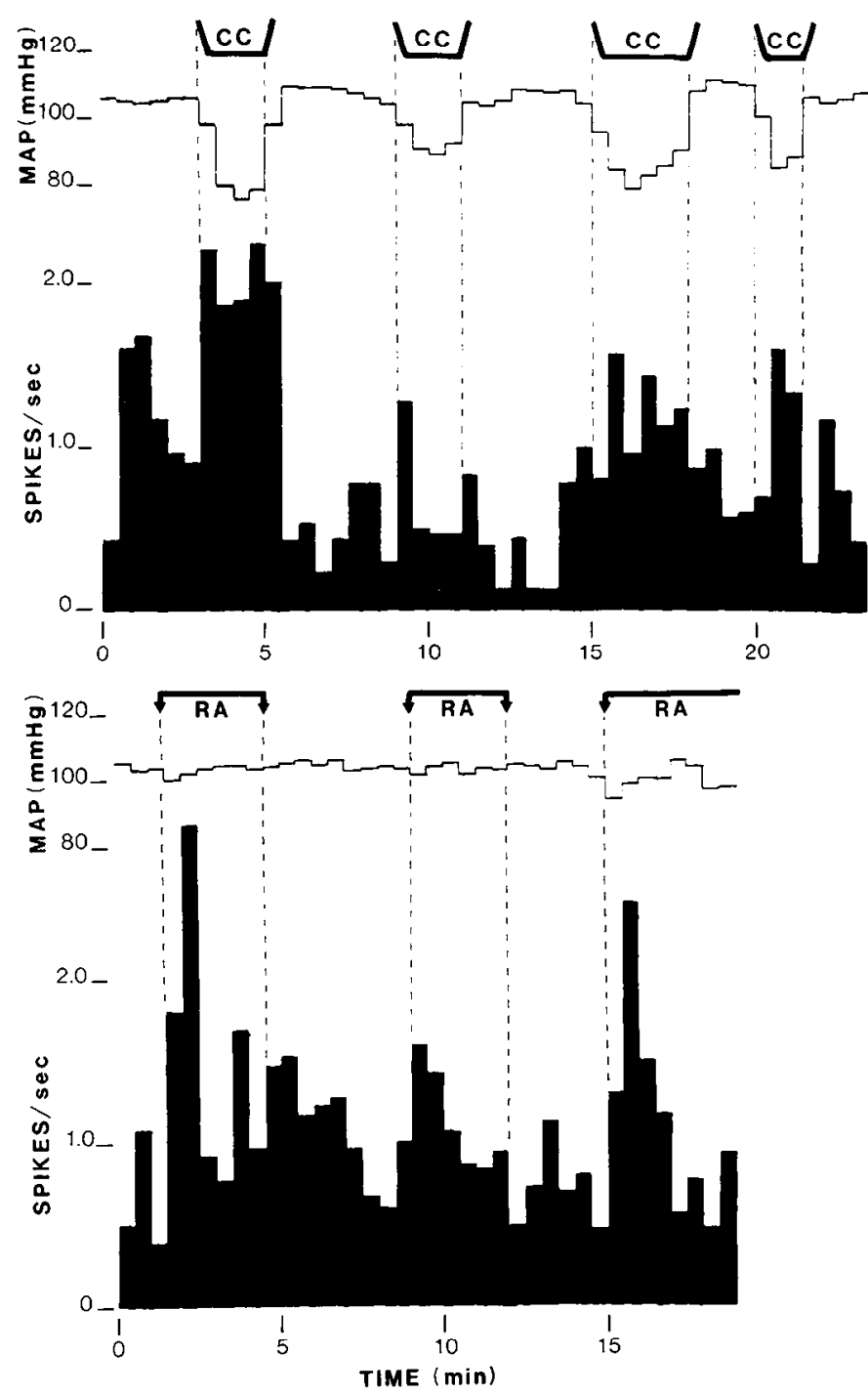

Figure 4. Firing rate of a single neuron during four trials of $\mathrm{CC}$ (top record) and during three trials of $\mathrm{RA}$ (bottom record). The cell was lost during last trial.

over a range extending from a lag of three 30 -sec periods to a lead of one 30 -sec period. The activity of only one neuron (facilitated during constriction) lagged the changes in arterial pressure by three 30 -sec periods.

Two neurons that responded to caval constriction were tested during partial control of arterial pressure by venous to arterial shunting, as described under "Materials and Methods." For one that was inhibited during constriction and that was facilitated during electrical stimulation of the pons, the relationship between the changes in arterial pressure and the rate of firing as defined by the linear regression between these variables did not change during partial control of arterial pressure. For the other, that was facilitated during constriction and that did not respond to pontine stimulation, the slope of the relationship between the neuron's activity and the arterial pressure was significantly reduced $(p<0.01)$ during partial control of arterial pressure as determined by comparing the linear regressions under the two con- 
ditions with analysis of co-variance (Snedecor and Cochran, 1967).

Response to pontine stimulation. Of the 18 neurons that responded to caval constriction, 13 were tested also with electrical stimulation in the dorsal rostral pons. In addition, all four neurons that responded to atrial pulsation alone were tested with pontine stimulation. Figure 5 (top record) shows a poststimulus-time histogram for the neuron whose response to atrial pulsation is shown in Figure 1. Electrical stimulation at a site in the dorsal raphe (see Fig. 8) increased the firing of this neuron between 9 and $80 \mathrm{msec}$ following the stimulus pulse. The neuron was also driven orthodromically from two other pontine sites that were lateral to the raphe with latencies of onset of 7 to $9 \mathrm{msec}$. In all, three neurons that responded to cardiovascular input were orthodromically activated by stimulation of a total of six pontine sites with latencies of onset ranging from 7 to $23 \mathrm{msec}$. Figure 5 (bottom record) shows a poststimulus-time histogram for a neuron that was located in the area of the paraventricular nucleus and that increased its activity in response to caval constriction. Stimulation at a site in the tegmentum anteroventral to the locus subceruleus (Maeda et al., 1973) suppressed totally the firing of this neuron from 20 to $100 \mathrm{msec}$. The neuron did not regain its prestimulus rate until $300 \mathrm{msec}$ following stimulation. One other neuron that responded to cardiovascular input was inhibited during stimulation of a single pontine site.
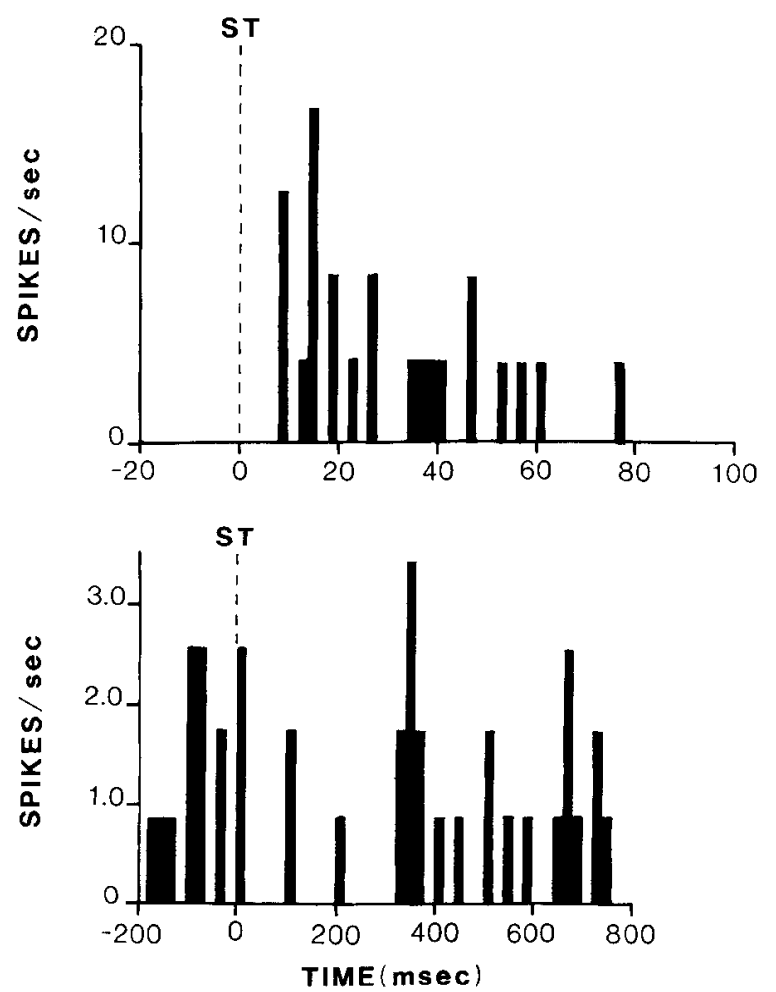

Figure 5. Poststimulus time histograms of a neuron that was facilitated orthodromically during stimulation in the pons (top record) and of a neuron that was inhibited during stimulation (bottom record).
Location of hypothalamic neurons. The hypothalamic sites at which neurons were recorded are shown in Figures 6 and 7 . Also shown are the areas that in previous studies (Grizzle et al., 1974; Maran et al., 1978; Gann et al., 1978, 1979; Carlson et al., 1980) were implicated in control of the release of ACTH. Areas in which electrical stimulation facilitated release are indicated with vertical shading and areas that were inhibitory are shown with cross-hatching. No neurons that responded to cardiovascular stimuli were caudal to the plane located $9.0 \mathrm{~mm}$ anterior to the intra-aural line. Of the 22 neurons that responded to cardiovascular stimuli all but four were within areas in which electrical stimulation was shown to modulate the release of $\mathrm{ACTH}$. The remaining four were immediately adjacent to these areas. Responsive neurons were identified within the posterior and dorsal hypothalamic areas, the dorsomedial, ventromedial, parvocellular, and paraventricular nuclei, and an area in the anterior hypothalamus lying near the supraoptic decussations. In general, neurons responding in one direction to a particular hemodynamic stimulus were located both in areas classified as facilitatory and in areas classified as inhibitory for the release of ACTH. However, of the three neurons within the paraventricular nucleus (PVN) that responded to caval constriction, all were facilitated. One of these cuff-responsive neurons failed to respond to right atrial pulsation as did two other neurons within the PVN that were tested with pulsation only. The only remaining neuron in this area failed to respond to caval constriction.

Location of sites of stimulation in the pons. Figure 8 shows those sites that were stimulated in the pons. The cross-hatching indicates areas in which neurons that responded to caval constriction were identified in a previous study (Ward et al., 1980). Of eight sites at which stimulation drove neurons that responded to cardiovascular stimuli in the present study, six were within 300 $\mu \mathrm{m}$ of the cross-hatched areas. Stimulation at 31 additional sites failed to drive neurons that responded to cardiovascular stimuli ( 29 sites), or drove cells that were considered not to be cardiovascular because they did not respond to caval constriction (two sites). Of these 31 , only seven were within $300 \mu \mathrm{m}$ of the cross-halched areas. This heterogeneity was significant $\left(p<0.01, \chi^{2}\right.$ test $)$.

\section{Discussion}

Hemodynamic stimuli and the classification of neurons. In the present study, both volume pulsation of the right atrium and constriction of the supradiaphragmatic vena cava were utilized to test hypothalamic neurons for input from cardiovascular receptors. Although slightly more than half of the neurons tested with caval constriction were responsive, only a small number of neurons responded to right atrial pulsation. Furthermore, five of six neurons that responded to caval constriction showed no response to atrial pulsation alone. Accordingly, those neurons that were not tested with caval constriction and that did not respond to atrial pulsation may have still received cardiovascular input. In contrast, a more certain 


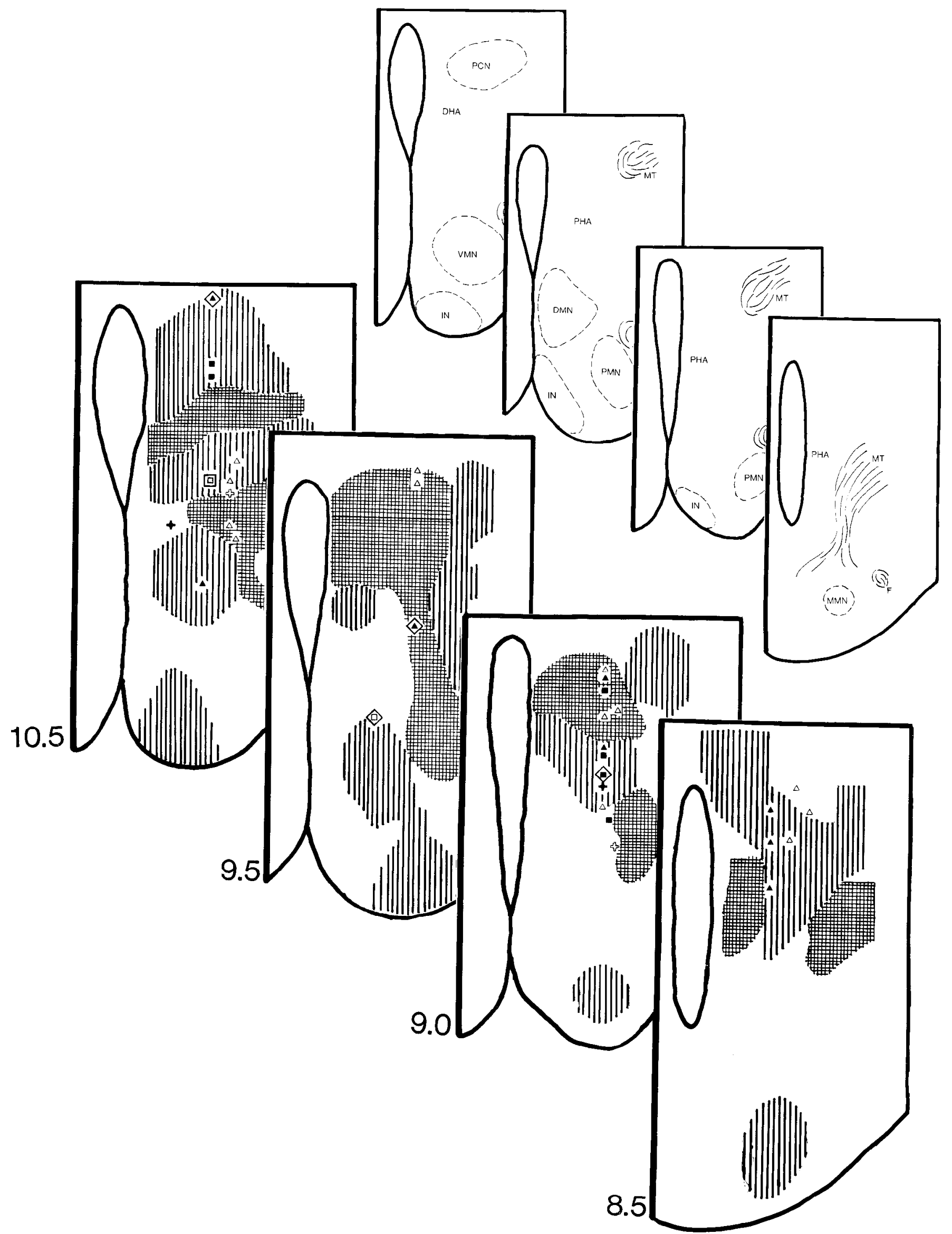




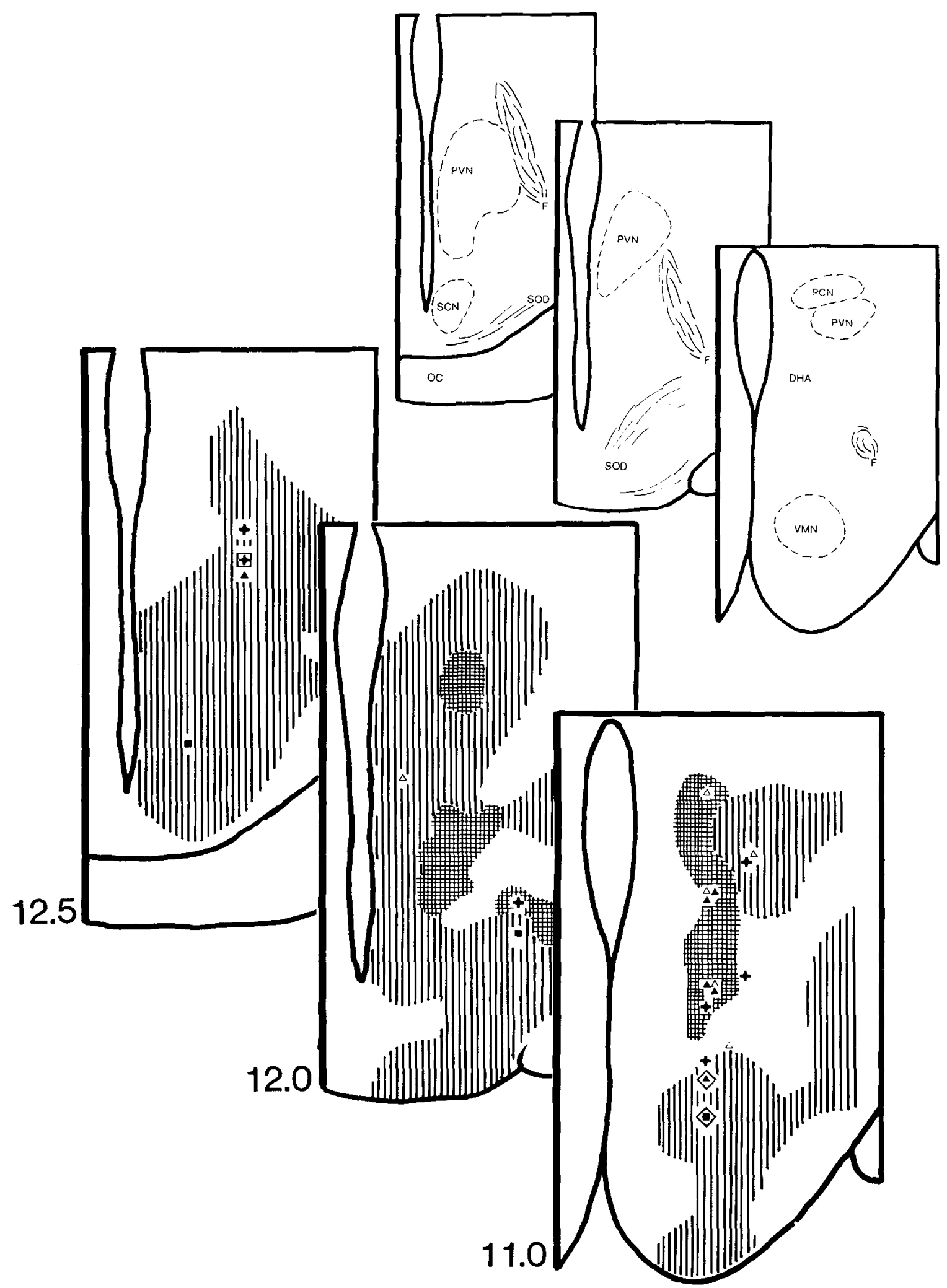

Figure 7. Locations of hypothalamic neurons projected onto coronal planes from 11.0 to $12.5 \mathrm{~mm}$ anterior to the intra-aural line. Symbols and shading are as in Figure 6. Anatomical structure is shown in the inset (upper right). Abbreviations are as in Figure 6 plus: $P V N$, paraventricular nucleus; $S O D$, supraoptic decussations; $S C N$; suprachiasmatic nucleus; $O C$, optic chiasm.

Figure 6. Locations of hypothalamic neurons projected onto coronal planes from 8.5 to $10.5 \mathrm{~mm}$ anterior to the intra-aural line. $\uparrow$, facilitated by $\mathrm{CC} ; \mathbf{\square}$, inhibited by $\mathrm{CC} ; \boldsymbol{\Delta}$, no response to $\mathrm{CC}$; 定, inhibited by $\mathrm{RA} ; \square$, facilitated by RA; $\triangle$, no response to RA, not tested with CC. Outlines around symbols indicate neurons responding to stimulation in the pons: $\diamond$, facilitated orthodromically; $\square$, inhibited. Shading indicates areas in which electrical stimulation was shown previously to modulate ACTH release: Vertical line shading, facilitation; inhibition. Anatomical structure is shown in the inset (upper right). F, fornix; $M T$, mamillothalamic tract; $P H A$, posterior hypothalamic area; $I N$, infundibular nucleus; $P M N$, premamillary nucleus; $D M N$, dorsomedial nucleus; $V M N$, ventromedial nucleus; $D H A$, dorsal hypothalamic area; $P C N$, parvocellular nucleus. 


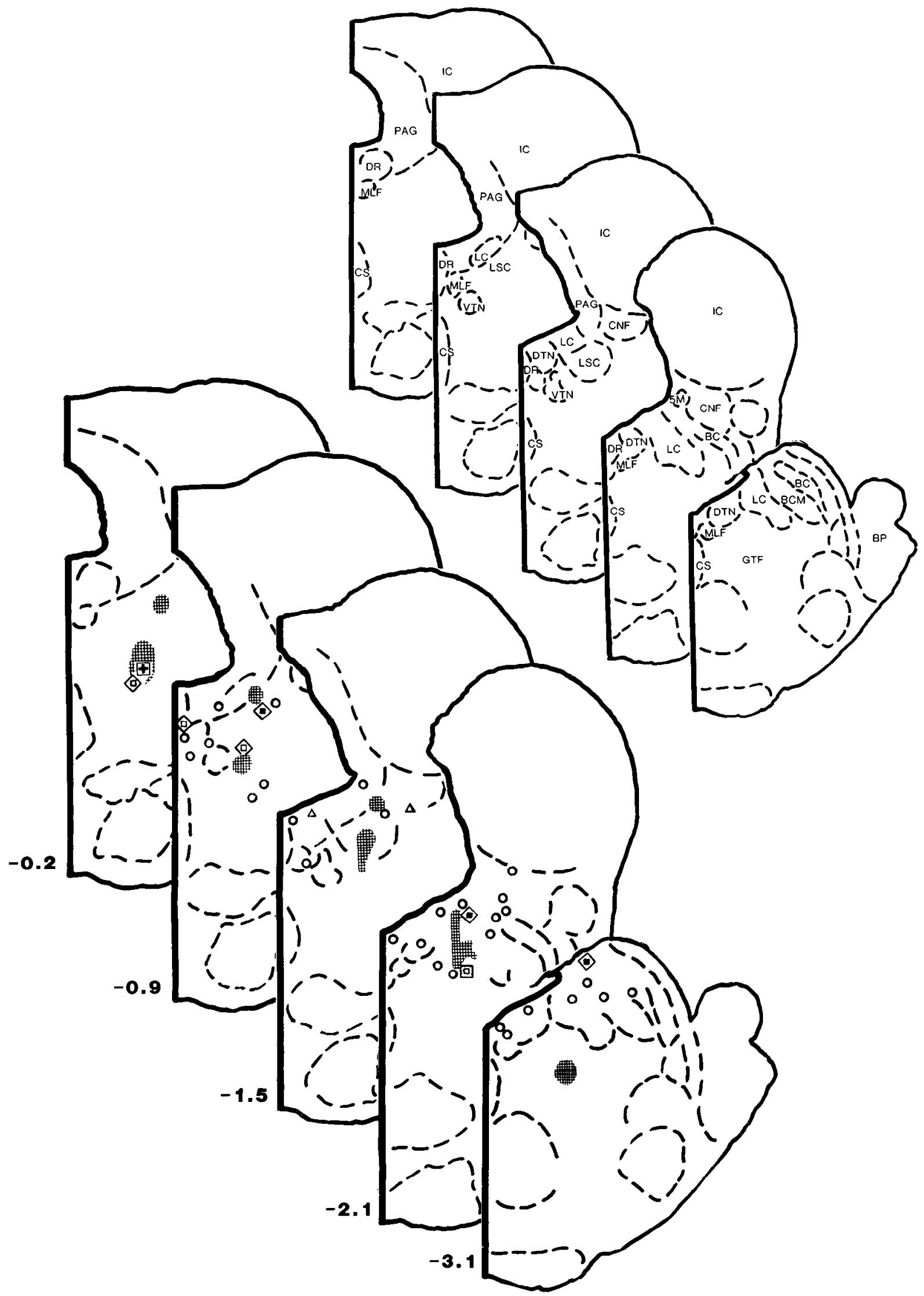

Figure 8. Location of sites of stimulation in the pons projected onto coronal planes from 0.2 to $3.1 \mathrm{~mm}$ posterior to the intraaural line. The central symbol indicates the hemodynamic response (as defined in Fig. 6) of a neuron responding to stimulation at the particular site. Outlines indicate the effect of stimulation: $\diamond$, orthodromic facilitation; $\square$, inhibition. Other symbols: $\triangle$, orthodromic facilitation of a neuron that did not respond to $\mathrm{CC}$; $\mathrm{O}$, no effect on neurons that responded to CC or to RA. Crosshatching shows the location of cardiovascular neurons identified previously. Anatomical structure is shown in the inset (upper right). GTF, gigantocellular tegmental field; $B P$, brachium pontis; $C S$, superior central nucleus; $M L F$, medial longitudinal fasciculus; $D T N$, dorsal tegmental nucleus; $L C$, locus ceruleus; $B C M$, medial parabrachial nucleus; $B C$, brachium conjunctivum; $D R$, dorsal raphe; $5 M$, mesencephalic trigeminal nucleus; $V T N$, ventral tegmental nucleus; $L S C$, locus subceruleus; $C N F$, cuneiform nucleus; $P A G$, periaqueductal gray; $I C$, inferior colliculus. 
classification of the remaining neurons as cardiovascular or as not cardiovascular was possible. In the present discussion, we have considered neurons that responded to either atrial pulsation or to caval constriction to receive cardiovascular input. Because caval constriction decreased the activity of both low- and high-pressure baroreceptors, we have considered only those neurons that did not respond to this stimulus to receive no cardiovascular input.

Patterns of response and organization of the hypothalamic neurons. For those cardiovascular neurons that responded to caval constriction, some general observations are of note. Of the nine neurons that decreased their firing during constriction of the inferior vena cava, the four neurons that were most posterior showed the smallest changes in firing rate. Thus, it appeared that the neurons inhibited by caval constriction within the posterior hypothalamic area had a relatively high threshold to decreased input from cardiovascular stretch receptors. For the nine neurons that increased their firing in response to caval constriction, the magnitude of their responses did not seem to vary with their location. However, seven of the nine neurons that were facilitated during caval constriction were in the rostral areas shown in Figure 7.

The cardiovascular neurons that we have identified were located in several areas of the medial hypothalamus and showed a variety of patterns of response. However, some of these patterns were similar to ones that have been observed previously (Baertschi et al., 1975; Gann et al., 1977, 1978; Ward et al., 1977, 1980) for neurons within the brainstem. In these previous studies, cells were considered as potentially involved in the control of ACTII release if their responses to hemodynamic stimuli correlated with the concomitant responses of ACTH and if their anatomical locations were in areas in which electrical stimulation evoked changes in ACTH release.

The neuron located in the dorsomedial nucleus (Fig. 1) had these properties. Its adaptation to repeated trials of pulsation was similar to that observed in medullary neurons (Ward et al., 1977). Furthermore, its apparent "off response" correlated with the transient increase in ACTH release that has been observed at the cessation of this stimulus (Baertschi et al., 1976; Gann et al., 1978). Finally, it was activated orthodromically (Fig. 5) by stimulation of sites lateral to and within the dorsal raphe (Fig. 8, two most rostral planes) at which electrical stimulation has been shown to inhibit ACTH release (Ward et al., 1976) and in which cells have been identified (Gann et al., 1977, 1978) that are activated by right atrial pulsation.

Another neuron potentially involved in the control of this hormone was shown in Figure 2. Its increase in firing during hemorrhage and its decrease in firing following 1 min of right atrial pulsation were parallel to the reported changes in ACTH release (Gann et al., 1978) that occur during these stimuli. Its failure to respond to right atrial pulsation unless the input to the arterial baroreceptors was reduced by carotid occlusion was similar to the finding of Grizzle et al. (1975) that most hypothalamic neurons responded to stretch of the right atrium only in the presence of carotid occlusion and to that of Baertschi et al. (1975) that many medullary neurons responded tc atrial pulsation only in the presence of hypovolemia. This behavior may explain our failure to identify more neurons that would respond to atrial pulsation alone and may account for the modest increase in ACTH release that follows a small hemorrhage in which arterial pressure does not decrease significantly (Gann et al., 1978).

Although a majority of the cardiovascular neurons were located in $\mathrm{ACTH}$-active areas, $\mathrm{ACTH}$-facilitatory areas contained some neurons that were facilitated and others that were inhibited by a particular hemodynamic stimulus as did ACTH-inhibitory areas. In contrast, in the brainstem, one pattern of neuronal response to a particular hemodynamic stimulus was shown to predominate in each ACTH-active area (Gann et al., 1978). However, in the hypothalamus, the presently reported mixed organization has been observed previously when areas were defined on the basis of either stimulated changes in ACTH release (Grizzle et al., 1975) or in arterial pressure (Thomas and Caleresu, 1972). These results may manifest the significant processing and integration that takes place in the hypothalamus.

The responses of other neurons to hemodynamic stimuli did not appear to correlate with the concomitant changes in AC'I'H release. In one neuron, for example, increased activity occurred both during caval constriction and at the onset of right atrial pulsation (Fig. 4). These stimuli have been shown to facilitate and to inhibit ACTH release, respectively. Because both of these stimuli lead to a sustained decrease in the firing of left atrial B receptors (Gann et al., 1978), this neuron may have been most sensitive to left atrial input. Baertschi and colleagues (1976) have shown that, during atrial pulsation, the left atrial receptors have a very small influence upon ACTH release relative to the right atrial receptors and to the arterial baroreceptors. Thus, this neuron may participate in the control of ACTH only during larger hemodynamic perturbations than occur during right atrial pulsation. It may also contribute to the control of other autonomic or neuroendocrine functions such as thirst (Zimmerman, et al., 1981) or the release of vasopressin (Brennan et al., 1971) in which left atrial receptors have been implicated.

Although only a small number of neurons were identified within the PVN, each of the cardiovascular neurons in this area increased its activity during caval constriction. Both this manipulation and electrical stimulation of this nucleus facilitate ACTH release. Because the PVN projects to the external zone of the median eminence (Olivecrona, 1957), and because some PVN neurons contain immunoreactivity (Kawata et al., 1982; Vigh et al., 1982) similar to the newly identified corticotropinreleasing factor (Vale et al., 1981), the release of this compound could stimulate the secretion of ACTH. In addition, other studies (Zimmerman, et al., 1977; Carlson et al., 1982; Gann and Carlson, 1982) have suggested that the release of vasopressin from the PVN may modulate ACTH release. Taken together, these findings suggest that the PVN may serve as a final pathway in the control of this hormone.

Input to hypothalamic neurons from the dorsal rostral pons. In a previous study, Ward et al. (1980) found that 
a majority of the neurons in the dorsal rostral pons increased their firing in response to caval constriction and showed an increase in the slope of the relationship between the changes in arterial pressure and in firing rate when the arterial pressure was partially controlled by venous-to-arterial shunting. None showed a decrease in this slope. The present finding of no change or a decrease in the slope of this relationship for the two neurons tested during partial control of arterial pressure suggests that some hypothalamic neurons receive cardiovascular input that originates from neurons other than those that were identified previously in the pons. This suggestion is supported further by our result that 12 of the 17 cardiovascular neurons that were tested with electrical stimulation in the pons were nonresponsive. Thus, some ascending signals may bypass the dorsal rostral pons. There is evidence for a direct projection from the nucleus tractus solitarius to the hypothalamus in both the rat (Ricardo and Koh, 1978) and the cat (Ciriello and Caleresu, 1980). Recent evidence from this laboratory suggests than an ascending pathway that travels near the surface of the fourth ventricle plays a role in the hemodynamic control of ACTH release (Lefcourt et al., 1979).

However, other information may pass through the dorsal rostral pons since five cardiovascular neurons responded orthodromically to pontine stimulation. The latencies of onset for the neurons that were facilitated were consistent with conduction velocities in the range of 0.5 to $2 \mathrm{~m} / \mathrm{sec}$ corresponding to unmyelinated or finely myelinated pathways. Kannan et al., (1981) have obtained velocities in the lower portion of this range for antidromic activation of rostral pontine neurons following stimulation of the supraoptic nucleus. However, we cannot rule out an oligosynaptic pathway. Since some neurons were driven by stimulation of several pontine sites, they might receive input from several pontine areas. Alternatively, the electrodes in such cases may have stimulated a single ascending pathway from several different loci.

Our failure to drive more cardiovascular neurons with pontine stimulation may have been related also to the location of the sites of stimulation. The distribution of these sites, as shown in Figure 8, suggests that only localized areas within the pons project to the cardiovascular neurons within the hypothalamus. All but two of the sites at which stimulation drove cardiovascular neurons were in or near pontine areas in which cardiovascular neurons were identified previously in the cat (Ward et al., 1980) and in the rat (Svensson and Thoren, 1979; Kannan et al., 1981). The majority of sites at which stimulation failed to drive cardiovascular neurons were remote from these areas, as were two other sites that drove neurons that were classified as noncardiovascular. Stimulation at a site in the dorsal raphe also drove a cardiovascular neuron. Preliminary studies (Gann et al., 1977, 1978) have identified cardiovascular neurons within this nucleus as well. The remaining site at which stimulation drove a cardiovascular neuron was in the parabrachial nucleus which receives an ascending projection from the nucleus tractus solitarius (Loewy and Burton, 1978; Ricardo and Koh, 1978). The pontine areas shown in Figure 8 also project rostrally; the parabrachial nucleus to the paraventricular, dorsomedial, ventromedial, and arcuate nuclei (Saper and Loewy, 1980), the locus ceruleus and locus subceruleus to the dorsomedial nucleus and the periventricular hypothalamus (Maeda et al., 1973), the dorsal raphe to the suprachiasmatic nucleus primarily and to other hypothalamic areas (Bobillier et al., 1975), and the reticular formation anteroventral to the locus subceruleus to the zona incerta and lateral hypothalamus (Robertson and Feiner, 1982). In line with these anatomical reports, the present results indicate that hemodynamic information from or traversing the dorsal rostral pons diverges to modulate several hypothalamic areas.

\section{References}

Baertschi, A. J., R. F. Munzer, D. G. Ward, R. N. Johnson, and D. S. Gann (1975) Right and left atrial B-fibers input to the medulla of the cat. Brain Res. 98: 189-193.

Baertschi, A. J., D. G. Ward, and D. S. Gann (1976) Role of atrial receptors in the control of ACTH. Am. J. Physiol. 231: 692-699.

Berman, A. L. (1968) The Brain Stem of the Cat, University of Wisconsin Press, Madison.

Bleier, R. (1961) The Hypothalamus of the Cat, The Johns Hopkins Press, Baltimore.

Bobillier, P., F. Petitjean, D. Salvert, M. Lighier, and S. Seguin (1975) Differential projections of the nucleus raphe dorsalis and nucleus raphe centralis as revealed by autoradiography. Brain Res. 85: 205-210.

Bolton, C. (1910) An experimental study of the pathology of cardiac dropsy, and its relation to that of local venous obstruction. J. Pathol. Bacteriol. 14: 49-89.

Brennan, L. A., Jr., R. L. Malvin, K. E. Jochim, and D. E. Roberts (1971) Influence of right and left atrial receptors on plasma concentrations of $\mathrm{ADH}$ and renin. Am. J. Physiol. 221: 273-278.

Carlson, D. E., A. Dornhorst, and D. S. Gann (1980) Organization of the lateral hypothalamus for control of adrenocor ticotropin release in the cat. Endocrinology 107: 961-969.

Carlson, D. E., A. Dornhorst, J. W. Maran, and D. S. Gann (1981) Hemodynamic signals arriving at the hypothalamus may traverse a discrete pontine area. Physiologist 24: 112.

Carlson, D. E., A. Dornhorst, S. M. Seif, A. G. Robinson, and D. S. Gann (1982) Vasopressin-dependent and -independent control of the release of adrenocorticotropin. Endocrinology 110: 680-682.

Ciriello, J., and F. R. Caleresu (1980) Autoradiographic study of ascending projections from cardiovascular sites in the nucleus tractus solitarii in the cat. Brain Res. 186: 448-453.

Cryer, G. L., and D. S. Gann (1974) Right atrial receptors mediate the adrenocortical response to small hemorrhage. Am. J. Physiol. 227: 325-328.

Gann, D. S., D. G. Ward, A. J. Baertschi, D. F. Carlson, and .J. W. Maran (1977) Neural control of ACTH release in response to hemorrhage. Ann. N. Y. Acad. Sci. 294: 477-497.

Gann, D. S., D. G. Ward, and D. E. Carlson (1978) Neural control of ACTH: A homeostatic reflex. Recent Prog. Horm. Res. 34: 357-400.

Gann, D. S., D. G. Ward, and D. E. Carlson (1979) Neural pathways controlling release of corticotropin (ACTH). In Inleraclion wilhin the Brain-Piluilary-Adrenocorlical System, M. T. Jones, B. Gillham, M. F. Dallman, and S. Chattopadhyay, eds., pp. 75-86, Academic Press, Inc., London.

Gann, D. S., and D. E. Carlson (1982) Role of vasopressin in 
the control of adrenocorticotropin secretion in vivo. In $\mathrm{Neu}$ roendocrinology of Vusopressin, Corticoliberin and Opiomelanocortins, A. J. Baertschi and J. J. Dreyfuss, eds., pp. 281-296, Academic Press, Inc., New York.

Grizzle, W. E., M. F. Dallman, L. P. Schramm, and D. S. Gann (1974) Inhibitory and facilitatory hypothalamic areas mediating ACTII release in the cat. Endocrinology 95: 14501461.

Grizzle, W. E., R. N. Johnson, L. P. Schramm, and D. S. Gann (1975) Hypothalamic cells in an area mediating ACTH release respond to right atrial stretch. Am. J. Physiol. 228: 1039-1045.

Hanker, J. S., P. E. Yates, C. B. Metz, and A. Rustioni (1977) A new specific, sensitive and non-carcinogenic reagent for the demonstration of horseradish peroxidase. Histochem. J. 9: 789-792.

Kannan, H., K. Yagi, and Y. Sawaki (1981) Pontine ncurones: Electrophysiological evidence of mediating carotid baroreceptor inputs to supraoptic neurones in rats. Exp. Brain Res. 42: $362-370$.

Kawata, M., K. Hashimoto, J. Takahara, and Y. Sano (1982) Immunohistochemical demonstration of the localization of corticotropin releasing factor-containing neurons in the hypothalamus of mammals including primates. Anat. Embryol. 165: 303-313.

Lefcourt, A. M., D. G. Ward, and D. S. Gann (1979) Discrete lesions of the dorsal rostral pons prevent ACTH increases after hemorrhage. Endocrinology, in press.

Loewy, A. D., and H. Burton (1978) Nuclei of the solitary tract: Efferent connections to the lower brainstem and spinal cord of the cat. J. Comp. Neurol. 181: 421-450.

Maeda, T., C. Pin, D. Salvert, M. Ligier, and M. Jouvet (1973) Les neurones contenant des catecholamines du tegmentum pontique et leur voies de projection chez le chat. Brain Res. 57: $119-152$.

Maran, J. W., D. E. Carlson, W. E. Grizzle, D. G. Ward, and D. S. Gann (1978) Organization of the medial hypothalamus for control of adrenocorticotropin in the cat. Endocrinology 103: $957-970$

Olivecrona, H. (1957) Paraventricular nucleus and pituitary gland. Acta Physiol. Scand. 40 (Suppl. 136): 1-178.

Ricardo, J. A., and E. T. Koh (1978) Anatomical evidence of direct projections from the nucleus of the solitary tract to the hypothalamus, amygdala, and other forebrain structures in the rat. Brain Res. 153: 1-26.
Robertson, R. T., and A. R. Feiner (1982) Diencephalic projections from the pontine reticular formation: Autoradiographic studies in the cat. Brain Res. 239: 3-16.

Saper, C. B., and A. D. Loewy (1980) Efferent connections of the parabrachial nucleus in the rat. Brain Res. 197: 291-317.

Snedecor, G. W., and W. G. Cochran (1967) Statistical Methods, pp. 419-446, The Iowa State Universily Press, Ames.

Snider, R. S., and W. T. Niemer (1961) A Stereotaxic Atlas of the Cat Brain, University of Chicago Press, Chicago.

Svensson, T. H., and P. Thoren (1979) Brain noradrenergic neurons in the locus coeruleus: Inhibition by blood volume load through vagal afferents. Brain Res. 172: 174-178.

Thomas, M. R., and F. R. Calaresu (1972) Responses of single units in the medial hypothalamus to electrical stimulation of the carotid sinus nerve in the cat. Brain Res. 44: 49-62.

Vale, W., J. Spiess, C. Rivier, and J. Rivier (1981) Characterization of a 41-residue ovine hypothalamic peptide that stimulates secretion of corticotropin and $\beta$-endorphin. Science 213: 1394-1397.

Vigh, S., I. Merchenthaler, I. Torres-Aleman, J. Sueiras-Diaz, D. H. Coy, W. H. Carter, P. Petrusz, and A. V. Shally (1982) Corticotropin releasing factor (CRF): Immunocytochemical localization and radioimmunoassay (RIA). Life Sci. 31: 24412448.

Ward, D. G., W. E. Grizzle, and D. S. Gann (1976) Inhibitory and facilitatory areas of the rostral pons mediating ACTH release in the cat. Endocrinology 99: 1220-1228.

Ward, D. G., A. J. Baertschi, and D. S. Gann (1977) Neurons in medullary areas controlling ACTH: Atrial input and rostral projections. Am. J. Physiol. 233: R116-R126.

Ward, D. G., A. M. Lefcourt, and D. S. Gann (1980) Neurons in the dorsal rostral pons process information about changes in venous return and in arterial pressure. Brain Res. 181: 7588.

Winer, B. J. (1971) Statistical Principles in Experimental Design, pp. 514-530, McGraw-Hill, New York.

Zimmerman, E. A., M. A. Stillman, L. D. Recht, J. L. Antunes, P. W. Carmel, and P. C. Goldsmith (1977) Vasopressin and corticotropin-releasing factor: An axonal pathway to portal capillaries in the zona externa of the median eminence containing vasopressin and its interaction with adrenal corticoids. Ann. N. Y. Acad. Sci. 297: 405-419.

Zimmerman, M. B., E. H. Blaine, and E. M. Stricker (1981) Water intake in hypovolemic sheep: Effects of crushing the left atrial appendage. Science 211: 489-491. 